\title{
Endovascular treatment of vertebral and basilar artery aneurysms with low-profile visualized intraluminal support device
}

\author{
Quanlong Hong ${ }^{1 \dagger}$, Wenqiang $\mathrm{Li}^{2,3+}$, Jing Ma ${ }^{4}$, Peng Jiang ${ }^{2^{*}}$ and Yisen Zhang ${ }^{2^{*}}$
}

\begin{abstract}
Background: The Low-profile Visualized Intraluminal Support (LVIS) device is a self-expanding, nitinol, single-braid, closed-cell device that was recently developed for endovascular embolization of intracranial aneurysms. However, current knowledge regarding the use of LVIS devices to treat vertebral and basilar artery aneurysms is limited. We aimed to evaluate the feasibility, efficacy, and safety of the LVIS device for treating vertebral and basilar artery aneurysms.
\end{abstract}

Methods: Between January 2015 and December 2017, patients with vertebral and basilar artery aneurysms treated using LVIS stents were enrolled in this study. We analyzed patients' demographic, clinical and aneurysmal characteristics, procedural details, complications, and angiographic and clinical follow-up results.

Results: We identified 63 patients with 64 vertebral and basilar artery aneurysms who underwent treatment with $(n=59)$ or without $(n=5)$ LVIS stenting, including 10 patients with ruptured aneurysms. Forty-one aneurysms were located at the vertebral artery, and 23 at the basilar artery. Intraprocedural-related complications developed in three (4.8\%) patients, while none of these patients developed morbidities or died during follow-up. Three patients developed post-procedural complications (4.8\%). Two patients experienced ischemic events immediately postprocedure. A minor permanent morbidity developed in one of the two patients (1.6\%). The mortality rate was $1.6 \%$, for that the patient died of brainstem hemorrhage after 1 month of follow-up. At a mean follow-up of 12.5 months, 39/43 (90.7\%) patients had stable or improved aneurysms, and four (9.3\%) had recanalized.

Conclusions: LVIS device of vertebral and basilar artery aneurysms may be an acceptable safety profile and may represent a reasonable treatment option in the short-term. Long-term and larger cohort studies are necessary to validate our results.

Keywords: Vertebral and basilar artery aneurysms, ${ }_{1}$ Low-profile visualized intraluminal support device ${ }_{2}$, stent ${ }_{3}$, Endovascular treatment 4 , complications $_{5}$

\section{Background}

Vertebral and basilar artery aneurysms with a poor natural history can cause subarachnoid hemorrhage and

\footnotetext{
* Correspondence: jiangpeng33@126.com; zhangyisen@bjtth.org

${ }^{+}$Quanlong Hong and Wenqiang Li contributed equally to this work.

${ }^{2}$ Department of Interventional Neuroradiology, Beijing Neurosurgical Institute and Beijing Tiantan Hospital, Capital Medical University, NansanhuanXilu 119, Fengtai District, Beijing 100070, China

Full list of author information is available at the end of the article
}

posterior circulation ischemia, resulting in high morbidity and mortality [1-3]. Treating vertebral and basilar artery aneurysms by clipping is usually challenging; therefore, endovascular coil embolization has been widely used for these aneurysms [4]. However, coiling alone to treat complex vertebral and basilar artery aneurysms remains controversial because of the poor longterm stability. To improve the efficacy of endovascular

C C The Author(s). 2021 Open Access This article is licensed under a Creative Commons Attribution 4.0 International License, which permits use, sharing, adaptation, distribution and reproduction in any medium or format, as long as you give appropriate credit to the original author(s) and the source, provide a link to the Creative Commons licence, and indicate if changes were made. The images or other third party material in this article are included in the article's Creative Commons licence, unless indicated otherwise in a credit line to the material. If material is not included in the article's Creative Commons licence and your intended use is not permitted by statutory regulation or exceeds the permitted use, you will need to obtain permission directly from the copyright holder. To view a copy of this licence, visit http://creativecommons.org/licenses/by/4.0/ The Creative Commons Public Domain Dedication waiver (http://creativecommons.org/publicdomain/zero/1.0/) applies to the data made available in this article, unless otherwise stated in a credit line to the data. 
treatment, intracranial stent was introduced to reduce recurrence rates by the mechanical barrier, flow diversion, and biological effects [5, 6]. The Low-profile Visualized Intraluminal Support device (LVIS ${ }^{\circ}$; MicroVention-Terumo, Tustin, CA) is a novel, selfexpanding, braided stent with a closed-cell construction made of nitinol, which could provide a higher degree of metal coverage (approximately 23\%) than conventional laser-cut stents such as the Enterprise (Codman Neurovascular, Miami Lake, FL), and Solitaire (Covidien, Irvine, $C A$ ) stents, but a lower degree of metal coverage than with flow diverters [7]. The LVIS design characteristics could improve the durability of endovascular treatment while avoiding impact on side branches [8]. However, the safety and efficacy of the LVIS stent to treat vertebral and basilar artery aneurysm requires further investigation. Therefore, we performed this study to evaluate the safety and efficacy of endovascular treatment for vertebral and basilar artery aneurysms using the LVIS stent.

\section{Methods}

This retrospective study was approved by the Institutional Review Board of Beijing Tiantan hospital. Verbal informed consent was obtained from the patients or their family members during hospitalization.

\section{Patient selection}

From January 2015 to December 2017, a total of 63 patients with 64 vertebral and basilar artery aneurysms treated with the LVIS stent were enrolled in this consecutive study. We recorded patients' clinical and aneurysmal characteristics, namely age, sex; cigarette smoking; alcohol intake; diabetes mellitus; hyperlipidemia; hypertension; aneurysm length, diameter, and maximum size; complications; follow-up interval; and angiographic and clinical follow-up results.

\section{Endovascular procedures}

Before the procedure, patients with unruptured vertebral and basilar artery aneurysms were premedicated with a dual-antiplatelet regimen ( $75 \mathrm{mg}$ of clopidogrel and 100 $\mathrm{mg}$ of aspirin daily) for at least 3 days. For patients with ruptured vertebral and basilar artery aneurysms, we administered a loading dose of antiplatelet medication (300 mg aspirin and $300 \mathrm{mg}$ clopidogrel) orally or through a stomach tube $4 \mathrm{~h}$ before the procedure. The endovascular procedures were then performed under general anesthesia with systemic heparin administration. Using the native and road map images, we deployed the LVIS stent to reconstruct the parent artery. If the vertebral and basilar artery aneurysmal sac contained sufficient space for coils, we performed coil embolization with the jailed-catheter technique. Treatment with the stent alone was preferred if the aneurysmal sac was not suitable for coil embolization. In accordance with the immediate angiographic findings just after deploying the first stent, subsequent overlapping stents were considered if a single stent was insufficient to remodel the blood flow [9]. After the procedure, dual antiplatelet agents (75 mg clopidogrel and $100 \mathrm{mg}$ aspirin) were provided orally once daily for 6 weeks, and $100 \mathrm{mg}$ aspirin was continued for the next 6 months.

\section{Clinical and angiographic follow-up}

A 6-month angiographic follow-up was recommended, and follow-up magnetic resonance angiography or computed tomography angiography was performed annually. Any aneurysm showing an increased percentage of contrast filling of the aneurysmal sac on follow-up angiography compared with the control angiogram was considered recurrence, and other aneurysms were regarded as stable or improved. The modified Rankin Scale (mRS) score was used to measure patients' clinical outcomes at follow-up visits or by telephone interview. We categorized patients' results as favorable (mRS, 0-2) or unfavorable (mRS, 3-6) in accordance with the last clinical follow-up findings.

\section{Results}

Patients' clinical and aneurysmal characteristics

Patients' baseline and aneurysmal characteristics are shown in Tables 1 and 2. Sixty-three consecutive patients with 64 vertebral and basilar artery aneurysms were included in the study, constituting 19 women and 44 men, ranging in age from 18 to 71 years (mean, 52.2 years). Twenty-five patients $(39.7 \%)$ presented with chronic headache/dizziness, 17 patients (27.0\%) with neurological deficit, 11 (17.5\%) aneurysms were incidental, and $10(15.9 \%)$ patients had subarachnoid hemorrhage. Patient comorbidities were smoking $(n=$ $24,38.1 \%)$, diabetes mellitus $(n=5,7.9 \%)$, hyperlipidemia $(n=6,9.5 \%)$, and hypertension $(n=33,52.4 \%)$. Fiftyseven aneurysms $(89.1 \%)$ were dissecting aneurysms, and 7 (10.9\%) were saccular aneurysms. Forty-one aneurysms (64.1\%) were located at the vertebral artery, and 23 $(35.9 \%)$ were located at the basilar artery. The mean length of the aneurysms was $11.1 \pm 7.4 \mathrm{~mm}$, and mean aneurysmal diameter was $7.9 \pm 4.3 \mathrm{~mm}$. There were 3 tiny aneurysms $(<3 \mathrm{~mm}), 30$ small aneurysms $(3-10$ $\mathrm{mm}), 26$ large aneurysms $(10-25 \mathrm{~mm})$, and 5 giant aneurysms ( $\geq 25 \mathrm{~mm}$ ).

\section{Angiographic outcomes}

The angiographic outcomes are summarized in Table 2. Of the 64 aneurysms with adequate initial embolization, 59 patients underwent LVIS-assisted coiling (92.2\%), and 5 received LVIS stents only (7.8\%); 48 received a single 
Table 1 Baseline information of the patients $(n=63)$ with vertebral and basilar artery aneurysms treated with stentassisted coil embolization using LVIS device

\begin{tabular}{|c|c|}
\hline Characteristics & No. (\%) \\
\hline Mean age (years) (mean \pm SD) & $52.2 \pm 10.9$ \\
\hline \multicolumn{2}{|l|}{ Gender } \\
\hline Women & $19(30.2)$ \\
\hline Men & $44(69.8)$ \\
\hline \multicolumn{2}{|l|}{ Main symptoms } \\
\hline Chronic Headache/dizziness & $25(39.7)$ \\
\hline Neurological deficits & $17(27.0)$ \\
\hline Incidental & $11(17.5)$ \\
\hline Acute SAH & $10(15.9)$ \\
\hline \multicolumn{2}{|l|}{ Risk factors } \\
\hline Smoking & $24(38.1)$ \\
\hline DM & $5(7.9)$ \\
\hline Hyperlipidemia & $6(9.5)$ \\
\hline $\mathrm{HBP}$ & $33(52.4)$ \\
\hline \multicolumn{2}{|l|}{ Pre-operative mRS scale $(n=63)$} \\
\hline 0 & $27(42.9)$ \\
\hline 1 & $23(36.5)$ \\
\hline 2 & $3(4.8)$ \\
\hline 3 & $7(11.1)$ \\
\hline 4 & $3(4.8)$ \\
\hline Clinical follow-up available & $62(98.4)$ \\
\hline \multicolumn{2}{|l|}{ mRS scale at lasted follow up $(n=42)$} \\
\hline 0 & $38(61.3)$ \\
\hline 1 & $21(33.9)$ \\
\hline 2 & $0(0.0)$ \\
\hline 3 & $1(1.6)$ \\
\hline 4 & $1(1.6)$ \\
\hline 5 & $0(0.0)$ \\
\hline 6 & $1(1.6)^{a}$ \\
\hline Follow-up period (months) (mean \pm SD (range)) & $24.3 \pm 10.6(12-38)$ \\
\hline
\end{tabular}

SAH Subarachnoid hemorrhage, HBP High blood pressure, DM Diabetes mellitus, SD Standard deviation, $m R S$ Modified Rankin Scale ${ }^{a}$ One patient died of brain stem failure caused by recurrence of a vertebral dissecting aneurysm

LVIS (75.0\%), and 16 received multiple LVIS stents (25.0\%). In the five patients receiving only an LVIS stent, all aneurysms were patent in the immediately postprocedure angiographic images; however, the residual contrast time in the aneurysm was increased, and the parent vessel was patent after treatment. In the followup angiographic images, the aneurysmal characteristics improved (Fig. 1). In the aneurysms treated with LVISassisted coiling, 55 (93.2\%) aneurysms had complete and near-complete occlusion at the end of the initial coil embolization, and 4 (6.8\%) showed incomplete
Table 2 The information of vertebrobasilar dissecting aneurysms, procedural details and outcomes $(n=64)^{a}$

\begin{tabular}{|c|c|}
\hline Characteristics & No. (\%) \\
\hline \multicolumn{2}{|l|}{ Aneurysm Type } \\
\hline Saccular & $7(10.9)$ \\
\hline Dissecting & $57(89.1)$ \\
\hline \multicolumn{2}{|l|}{ Ruptured } \\
\hline Yes & $10(15.6)$ \\
\hline No & $54(84.4)$ \\
\hline \multicolumn{2}{|l|}{ Aneurysm location } \\
\hline Vertebral artery & $41(64.1)$ \\
\hline Basilar artery & $23(35.9)$ \\
\hline Mean aneurysm length $(\mathrm{mm})($ mean $\pm \mathrm{SD})$ & $11.1 \pm 7.4$ \\
\hline Mean aneurysm diameter $(\mathrm{mm})($ mean $\pm \mathrm{SD})$ & $7.9 \pm 4.3$ \\
\hline \multicolumn{2}{|l|}{ Aneurysm size (mm) } \\
\hline Tiny $(<3)$ & $3(4.7)$ \\
\hline Small $(\geq 3,<10)$ & $30(46.9)$ \\
\hline Large $(\geq 10,<25)$ & $26(40.6)$ \\
\hline Giant $(\geq 25)$ & $5(7.8)$ \\
\hline \multicolumn{2}{|l|}{ Procedure } \\
\hline LVIS stent only (n (\%)) & $5(7.8)$ \\
\hline LVIS stent and coiling (n (\%)) & $59(92.2)$ \\
\hline \multicolumn{2}{|l|}{ No of stents (n (\%)) } \\
\hline Single LVIS & $48(75.0)$ \\
\hline Multiple LVIS & $16(25.0)$ \\
\hline In-stent stenosis (n (\%)) & $2(3.2 \%)$ \\
\hline \multicolumn{2}{|l|}{ Raymond Scale $(n=64)$} \\
\hline 1 & $32(50.0)$ \\
\hline 2 & $23(35.9)$ \\
\hline 3 & $9(14.1)$ \\
\hline Angiographic follow-up available & $43(67.2)$ \\
\hline Follow-up duration (months) (mean $\pm \mathrm{SD}$ (range)) & $12.5 \pm 9.6(5-30)$ \\
\hline \multicolumn{2}{|l|}{ Angiographic follow up outcome $(n=43)$} \\
\hline Stable or improved & $39(90.7)$ \\
\hline Recurrence & $4(9.3)$ \\
\hline
\end{tabular}

${ }^{a}$ One patient had two aneurysms treated with LVIS stent (63 patients with 64 aneurysms) and this patient has Angiographic follow-up

occlusion. After discharge, 43 patients with 44 aneurysms (67.2\%) were followed with digital subtraction angiography from 5 to 30 months (mean \pm standard deviation, $12.5+9.6$ months). The follow-up images showed that 39 patients had stable or improved aneurysms (90.7\%), and only 4 (9.3\%) had recanalized. Three of the recanalized patients were treated with repeat coiling, and one received an additional LVIS stent. All of the recanalized patients achieved complete occlusion in the final follow-up images. Six-month follow-up images in one patient with a recanalized aneurysm treated with an 


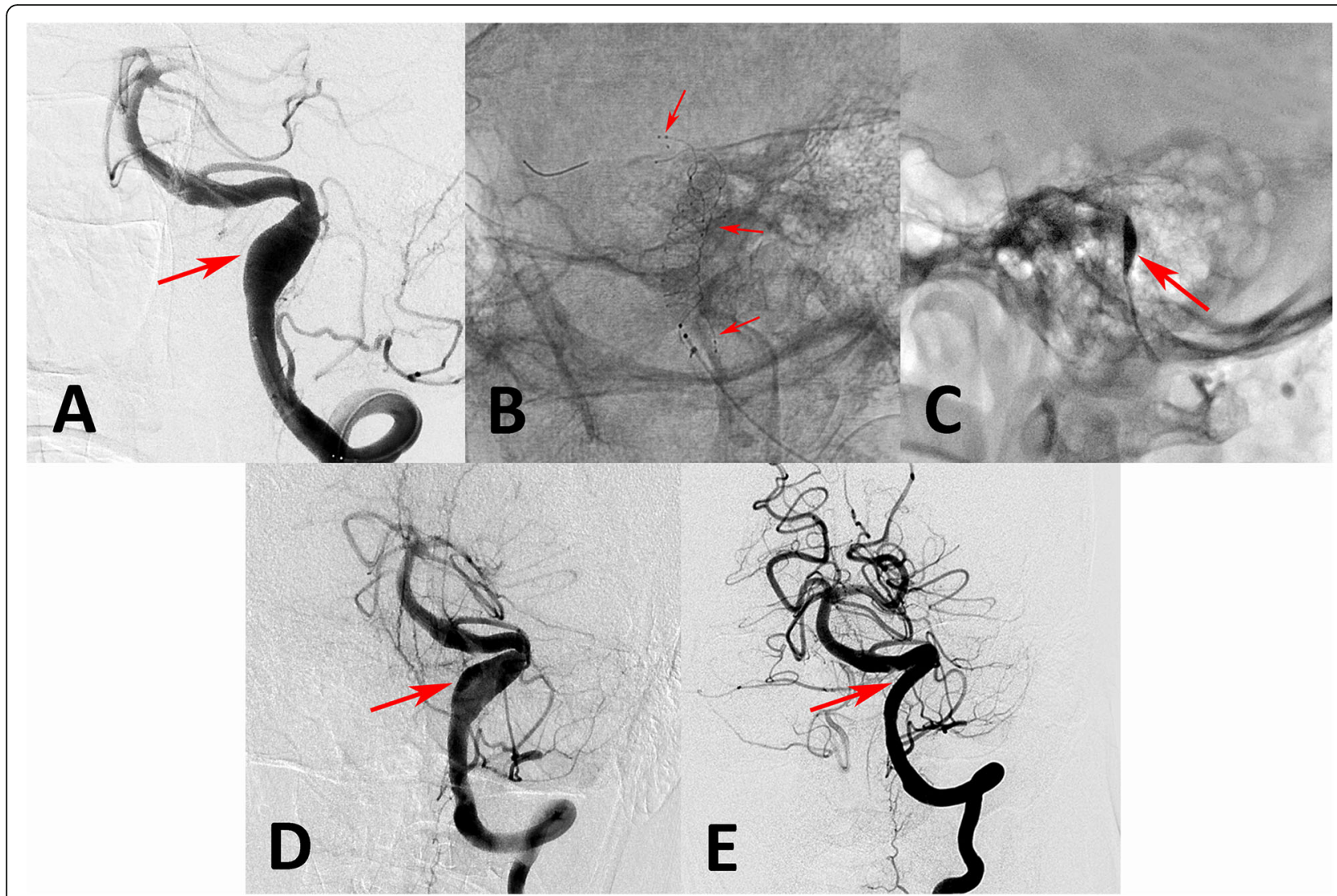

Fig. 1 A vertebral artery aneurysm was treated with two LVIS stents without coiling. Compared with the anteroposterior position in the preoperative angiographic images (a arrow), after we deployed two overlapping LVIS stents (b arrows), the contrast residual time in the aneurysm increased (c arrow). However, the aneurysm was still patent in immediate post-procedure angiographic images (d arrow). At the 6-month followup angiography, the aneurysm was completely occluded (e arrow)

LVIS stent with adjunctive coiling for a saccular basilar apex aneurysm showed that the aneurysm had recanalized. Repeat coiling was performed in this patient, and complete occlusion was observed in the final follow-up images (Fig. 2).

\section{Procedural complications and clinical outcomes}

Intraprocedural or postprocedural complications occurred in 6 patients (9.6\%): intraprocedural in $3(4.8 \%)$ and postprocedural in $3(4.8 \%)$. Regarding the intraprocedural complications, the LVIS stent was successfully deployed into the correct position across the entire length of the aneurysm in all patients. However, one patient developed partial coil loop protrusions, one developed in-stent thrombosis, and the stent failed to open completely in one patient. The coil loop was stable without pulsatile movement, and no additional stent placement was performed. We administered $10 \mu \mathrm{g} / \mathrm{kg}$ tirofiban (Grand Pharmaceutical Co Ltd., China) intraarterially during the procedure for the patient with instent thrombosis, and we performed balloon angioplasty for the insufficient apposition in the patient with the incompletely opened stent, after which, the stent remained incompletely open. Two patients had in-stent stenosis (3.2\%). However, the parent artery in the three patients remained patient, and none of the patients experienced neurological deficits after the procedures or during the clinical follow-up.

Post-procedural complications developed in three patients (4.8\%), namely, two delayed thromboembolic events and one distal arterial hemorrhage. The two ischemic events developed immediately after the procedure, and resulted in one patient sustaining minor permanent morbidity (1.6\%). This patient had a $7-\mathrm{mm}$ fusiform aneurysm at the left vertebral artery that involved the posterior inferior cerebellar artery, which was treated with LVIS stent-assisted coiling. The patient suffered from mild vertigo and hoarseness after the procedure, and recovered by the last follow-up (mRS score of 0 ). Another complication occurred in a patient with a basilar tip saccular aneurysm who developed oculomotor nerve palsy after LVIS stent-assisted coiling. The parent artery was patent in follow-up imaging, although the oculomotor nerve palsy persisted on the right side, 


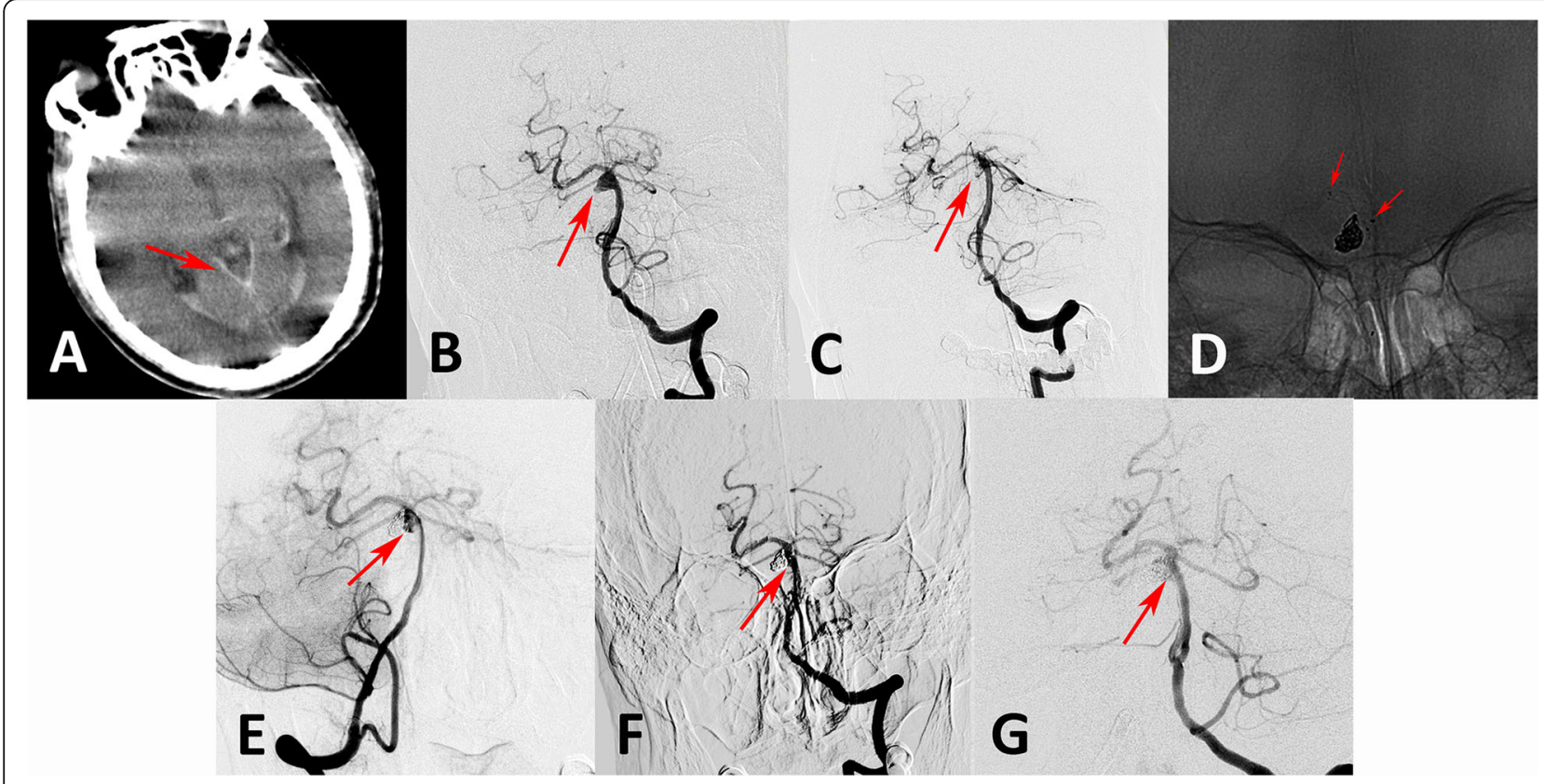

Fig. 2 A ruptured basilar trunk aneurysm with a daughter sac was treated with LVIS-assisted coiling, and computed tomography confirmed subarachnoid hemorrhage (a arrow). Compared with the anteroposterior position in the preoperative angiographic images (b arrow), the aneurysm was completely occluded after treatment in the immediately post-procedure angiograph (c arrow). The LVIS stent was placed across the neck of the aneurysm followed by embolization with coils (d). At the 6-month follow-up angiography, the aneurysm had recanalized (e arrow). Repeat coiling was performed, and the residual aneurysm neck was occluded completely (f arrow). At the 7-month follow-up angiography, the aneurysm was stable and completely occluded (g arrow)

which affected the patient's status at discharge (mRS score of 2). The post-procedure mortality rate was $1.6 \%$ because this patient died of brainstem hemorrhage after 1-month. Six-two patients (98.4\%) had clinical outcome available at lasted follow-up, and 59 patients (95.2\%) had favorable clinical outcomes (mRS score of $0-2$ ). We further analyzed the risk factors in aneurysms with recanalization and complications, while there is no significant risk factor associated with aneurysm recanalization and complication (Supplement Table 1).

\section{Discussion}

The LVIS device is a novel, self-expanding, braided stent that provides approximately $23 \%$ surface metal coverage. The smaller cell structure and higher metal coverage might result in better flow diversion compared with other currently available coil-assist stents. However, some factors, like perforator rich areas, should be taken into consideration, especially overlapping stents technique is used. In this study, our experience with the LVIS stent demonstrated that the technology can be safely used to treat vertebral and basilar artery aneurysms, with good clinical outcomes and follow-up occlusion rates.

\section{Angiographic results at follow-up}

In this study, the immediate angiographic results demonstrated relatively lower rates of complete occlusion (50\%); however, the progression to complete occlusion was quite satisfactory, with a high rate of $90.7 \%$ at the midterm follow-up. King et al. [10] reported the results of a literature review comparing the most widely-used intracranial stents (Neuroform and Enterprise) and found that initial and final complete occlusion was seen in 52.7 and $61.1 \%$, respectively, of the patients treated with Neuroform stents. The final complete occlusion rate for the Enterprise stent was higher at follow-up (74.7\%). In a recent prospective multicenter study of cerebral aneurysms treated with LVIS stents, the authors reported a total aneurysm occlusion rate of $91 \%$ on immediate postprocedure angiograms, and $92.4 \%$ at followup [11]. Cho et al. [12] reported that the complete obliteration rate of aneurysms undergoing LVIS-assisted coil embolization was $92.6 \%$ at the 6-month follow-up. However, these studies did not analyze the complete occlusion rate of vertebral and basilar artery aneurysms, separately. Wang et al. $[8,13]$ reported a series of patients treated with the LVIS device in vertebral and basilar artery aneurysms, with a complete occlusion rate in basilar artery aneurysms of $65 \%$ at 6.9 months of follow- 
up, and a complete occlusion rate in vertebral artery dissecting aneurysms of $76.7 \%$ at 8.3 months of follow-up. However, the follow-up periods might have been too short to identify a higher complete occlusion rate. In our study, the follow-up period was 12.5 months, which might explain why the complete occlusion rate at follow-up in our patients with vertebral and basilar artery aneurysms was higher than in previous studies. However, our patient cohort was relatively small, and the follow-up was still short. In addition, several studies reported that a higher rate of intra-procedural in-stent thrombosis for the LVIS stent, which ranged from 6.3$13.7 \%$ [14-16]. Gross et al. [17] reported that the Neuroform Atlas stent might have greater obliteration rates and lower in-stent stenosis in the treatment of aneurysm. Thus, stent assisted coiling with other stents (such as Neuroform Atlas stent) might remain treatment options in some posterior circulation aneurysms and given the lower metal coverage with lower in-stent stenosis rate. Further studies are needed to confirm its efficacy and safety.

Flow diversion has emerged as a treatment option for vertebral and basilar artery aneurysms, although this is currently an off-label use [18]. Flow diversion stents are mechanistically unique in that they have low porosity with obvious hemodynamic effects on aneurysms, which results in parent vessel reconstruction and intraaneurysmal thrombosis, resolving the aneurysm. Several studies reported that flow diversion is a feasible and effective treatment for aneurysms in the vertebral and basilar artery. However, flow diversion in vertebral and basilar artery aneurysms carries a high risk of periprocedural stroke, and might be associated with high overall mortality [18-20]. Numerous studies showed that LVIS stents also have flow diverting effects to minimize aneurysmal hemodynamics [7, 21]. Wang et al. [7] quantified the flow diverting effects of the LVIS device, and compared the effect with the Pipeline device (Chestnut Medical Technologies, Menlo Park, CA) and the Enterprise stent. The authors found that the flow diverting effect of a single LVIS stent caused more flow reductions than the double-Enterprise stent but less than with a Pipeline device, and that double-LVIS stenting resulted in better flow diversion than a Pipeline device. However, the findings in that study were based on virtual models, and were not compared with clinical outcomes. $\mathrm{Li}$ et al. [21] selected two consecutive clinical cases to compare the hemodynamic aneurysmal changes after stentassisted coiling between patients with the LVIS vs an Enterprise stent. The authors found that aneurysms treated with the LVIS device had greater reductions in blood flow velocity at the neck plane and within the aneurysm, and that such hemodynamic changes might explain the higher complete occlusion rate and lower recanalization rate in intracranial aneurysms treated with the LVIS device. The clinical results in our study also supported this potential mechanism. In immediate postprocedural angiography images, the complete and near-complete occlusion rate was $93.2 \%$ in patients treated with LVISassisted coiling, and the contrast residual time in the aneurysm was increased in all patients treated with LVIS stenting, alone. Importantly, $90.7 \%$ of the patients with follow-up images had stable or improved aneurysms.

\section{Complications}

Aneurysms in the vertebral and basilar artery are rare but are associated with substantial morbidity and mortality. The risk of rupture in vertebral and basilar artery aneurysms is also higher compared with aneurysms in the anterior circulation, and managing vertebral and basilar artery aneurysms is particularly challenging. In the International Study on Unruptured Intracranial Aneurysms guidelines, aneurysm location in the vertebral and basilar artery was a predictor of poor outcomes with endovascular treatment [22]. The LVIS device is a novel, self-expanding stent, and limited data provide evidence supporting the use of the LVIS stent in the reconstructive treatment of vertebral and basilar artery aneurysms. In our study, the overall procedure-related complication rate was $9.6 \%$, which is comparable to other studies evaluating LVIS stents in vertebral and basilar artery aneurysms $[8,13]$. The risk of thromboembolic complications is relatively higher in vertebral and basilar artery aneurysms compared with anterior circulation aneurysms because the vertebral and basilar artery arteries have a rich collateral system, and a stent might disrupt the flow in collateral arteries. Incomplete stent expansion is a common cause of thromboembolic complications, especially when using wire-braided stents. In our study, the use of the LVIS device was feasible, with a high technical success rate of $98.4 \%$. The stent failed to expand adequately in only one patient. Cho et al. [12] suggested that the LVIS stent might fold or twist in the tortuous anatomy and acute curve of the parent artery because of incomplete flaring of the braided closed-cell structure. In the study, the rate of thromboembolic complications following LVIS stenting was $4.8 \%$, which is comparable to the rate of thromboembolic events of $4.9 \%$, in a previous systematic review [23]. However, the rate of thromboembolic complications is higher with flow diverter stents (11.0\%) [24]. The possible reason for the lower rate of thromboembolic complications with the LVIS stent might be that this stent had lower metal coverage. The advantages of LVIS stent include offering better visualization, improving wall apposition, and re-sheathable compared with other devices. Importantly, one patient in our study died of distal arterial hemorrhage. Previous studies have strongly suggested that excessive platelet 
inhibition was associated with an increased risk of hemorrhagic complications $[25,26]$. However, platelet function testing was not performed in this study, and this testing might be helpful in the clinical determination of hemorrhagic risks before endovascular procedures. In our center, for the complex aneurysms located at vertebral and basilar artery (such as giant dissecting aneurysm, aneurysm involved vertebral-basilar junction, etc.), internal trapping technique was the initial treatment of choice for the lower recanalization rate. However, internal trapping might be not an appropriate treatment with several anatomic factors of the parent artery, including the involved important arterial branches, the dominance of the affected vertebral artery, and the insufficiency of the collateral blood supply. Flow diverter is an alternative treatment for the patients who were not suitable to internal trapping, for which treatment with flow diverter had a higher complete occlusion rate and better clinical outcome compared with conventional endovascular treatment [27]. However, flow diverter applied in the vertebral and basilar artery was off-label for high risk of thromboembolic events. Similarly, two or more overlapping LVIS stents might also give the high risk of thromboembolic complications. The clinicians should be cautious in the decision-making process regarding whether or when a flow diverter should be applied in the vertebral and basilar artery. Apart from the above treatments, stent-assisted coiling might be considered for the aneurysm of classic dissecting aneurysm and segmental ectasia, and had a favorable angiographic outcome [28].

This study has several limitations. First, this was a single-center retrospective study, and might include an inherent bias in patient selection. Second, the small sample size and mid-term follow-up may have influenced our findings, and a prospective study with a larger sample size is needed for validation. Third, other techniques such as internal trapping or flow diverters should be compared in future studies to evaluate the safety and efficacy of the LVIS device in vertebral and basilar artery aneurysms. Fourth, platelet function monitoring during dualantiplatelet therapy was not standard procedure in this study, and a multicenter prospective trial may best evaluate the clinical usefulness of platelet function testing.

\section{Conclusions}

Our study demonstrated the feasibility and safety of LVIS devices for treating vertebral and basilar artery aneurysms, and the mid-term complete occlusion rate, morbidity and mortality rates were acceptable. The LVIS stent was an acceptable safety profile and may represent a reasonable treatment option in the patients with vertebral and basilar artery aneurysms. Long-term and larger cohort studies are needed to validate our results.
Abbreviations

LVIS: Low-profile Visualized Intraluminal Support; mRS: Modified Rankin Scale

\section{Supplementary Information}

The online version contains supplementary material available at https://doi org/10.1186/s12883-021-02180-1.

Additional file 1: Supplemental Table 1. Univariate analysis of the risk factors in aneurysms with recanalization and complications.

\section{Acknowledgments}

None.

Authors' contributions

$\mathrm{QH}$ and $\mathrm{WL}$ contributed to the preparation of the manuscript and data collection. YZ, PJ and JM contributed to the experimental design and manuscript revision. The author(s) read and approved the final manuscript.

\section{Funding}

This work was supported by the National Natural Science Foundation of China (81801158 and 81501483), Youth Scientist Project of Beijing Tiantan Hospital (Award number: YSP201904), Shanghai Natural Science Foundation (18ZR1435400).

\section{Availability of data and materials}

All datasets generated for this study are included in the manuscript and/or the supplementary file.

\section{Declarations}

Ethics approval and consent to participate

The ethics committee of Beijing Tiantan Hospital approved this study and verbal informed consent was obtained from each study patient or their relatives, because this study is a retrospective study.

Consent for publication

Not applicable.

\section{Competing interests}

The authors declare that the research was conducted in the absence of any commercial or financial relationships that could be construed as a potential conflict of interest.

\section{Author details}

'Department of Neurology, The First Hospital of Quanzhou Affiliated to Fujian Medical University, Quanzhou, China. ${ }^{2}$ Department of Interventional Neuroradiology, Beijing Neurosurgical Institute and Beijing Tiantan Hospital, Capital Medical University, NansanhuanXilu 119, Fengtai District, Beijing 100070, China. ${ }^{3}$ Department of Neurosurgery, The First Affiliated Hospital of Zhengzhou University, Zhengzhou, Henan, China. ${ }^{4}$ Department of Echocardiography, Shanghai Xuhui Central Hospital, Zhongshan-Xuhui Hospital, Fudan University, Shanghai, China.

Received: 1 August 2020 Accepted: 2 April 2021

Published online: 15 May 2021

References

1. Wang K, Tian Z, Chen J, Liu J, Wang Y, Zhang H, et al. Risk factors of recurrence after stent(s)-assisted coiling of intracranial vertebrobasilar dissecting aneurysms: a multicenter study. Front Neurol. 2017;8:482. https:// doi.org/10.3389/fneur.2017.00482

2. Jin SC, Kwon DH, Choi CG, Ahn JS, Kwun BD. Endovascular strategies for vertebrobasilar dissecting aneurysms. AJNR Am J Neuroradiol. 2009;30(8): 1518-23. https://doi.org/10.3174/ajnr.A1621.

3. Kim BM, Shin YS, Kim SH, Suh SH, Ihn YK, Kim Dl, et al. Incidence and risk factors of recurrence after endovascular treatment of intracranial vertebrobasilar dissecting aneurysms. Stroke. 2011:42(9):2425-30. https://doi. org/10.1161/STROKEAHA.111.617381. 
4. Sikkema T, Uyttenboogaart M, Eshghi O, de Keyser J, Brouns R, van Dijk JMC, et al. Intracranial artery dissection. Eur J Neurol. 2014;21(6):820-6. https://doi. org/10.1111/ene.12384.

5. Feng Z, Fang $Y, X u Y$, Hong B, Zhao W, Liu J, et al. The safety and efficacy of low profile visualized intraluminal support (LVIS) stents in assisting coil embolization of intracranial saccular aneurysms: a single center experience. J Neurointerv Surg. 2016;8(11):1192-6. https://doi.org/10.1136/neurintsurg-2 015-012090.

6. $\quad$ Yang $H$, Sun $Y$, Jiang $Y, L v X$, Zhao $Y$, Li Y, et al. Comparison of stent-assisted coiling vs coiling alone in 563 intracranial aneurysms: safety and efficacy at a high-volume center. Neurosurgery. 2015;77(2):241-7; discussion 247. https://doi.org/10.1227/NEU.0000000000000765.

7. Wang C, Tian Z, Liu J, Jing L, Paliwal N, Wang S, et al. Flow diverter effect of LVIS stent on cerebral aneurysm hemodynamics: a comparison with Enterprise stents and the Pipeline device. J Transl Med. 2016;14(1):199. https://doi.org/10.1186/s12967-016-0959-9.

8. Wang CC, Fang YB, Zhang P, Zhu X, Hong B, Xu Y, et al. Reconstructive endovascular treatment of vertebral artery dissecting aneurysms with the low-profile visualized intraluminal support (LVIS) device. PLoS One. 2017; 12(6):e0180079. https://doi.org/10.1371/journal.pone.0180079.

9. Zhang $Y$, LV M, Zhao $C$, Zhang $Y$, Yang $X, W u$ Z. Endovascular treatment of ruptured vertebrobasilar dissecting aneurysms: review of 40 consecutive cases. Neurol India. 2016;64(Suppl):S52-61.

10. King B, Vaziri S, Singla A, Fargen KM, Mocco J. Clinical and angiographic outcomes after stent-assisted coiling of cerebral aneurysms with Enterprise and Neuroform stents: a comparative analysis of the literature. J Neurointery Surg. 2015;7(12):905-9. https://doi.org/10.1136/neurintsurg-2014-011457.

11. Iosif C, Piotin M, AUID- Oho, et al. Safety and effectiveness of the low profile visualized intraluminal support (LVIS and LVIS Jr) devices in the endovascular treatment of intracranial aneurysms: results of the TRAIL multicenter observational study. J Neurointerv Surg. 2018;10(7):675-81. https://doi.org/10.1136/neurintsurg-2017-013375.

12. Cho YD, Sohn CH, Kang HS, Kim JE, Cho WS, Hwang G, et al. Coil embolization of intracranial saccular aneurysms using the low-profile visualized intraluminal support (LVIS) device. Neuroradiology. 2014;56(7): 543-51. https://doi.org/10.1007/s00234-014-1363-x.

13. Wang C, Wu Y, Feng Z, Wang J, Li Q, Zhao R, et al. Preliminary experience with the use of low profile visualized intraluminal support device in basilar artery for aneurysm treatment. J Neurointerv Surg. 2019;11(4):405-10. https://doi.org/10.1136/neurintsurg-2018-014393.

14. Shankar JJS, Quateen A, Weill A, Tampieri D, del Pilar Cortes M, Fahed R, et al. Canadian Registry of LVIS Jr for Treatment of Intracranial Aneurysms (CaRLA). J Neurointerv Surg. 2017;9(9):849-53. https://doi.org/10.1136/ neurintsurg-2016-012611.

15. Behme D, Weber A, Kowoll A, Berlis A, Burke TH, Weber W. Low-profile visualized intraluminal support device (LVIS Jr) as a novel tool in the treatment of wide-necked intracranial aneurysms: initial experience in 32 cases. J Neurointerv Surg. 2015;7(4):281-5. https://doi.org/10.1136/ neurintsurg-2014-011157.

16. Wang J, Vargas J, Spiotta A, Chaudry I, Turner RD, Lena J, et al. Stentassisted coiling of cerebral aneurysms: a single-center clinical and angiographic analysis. J Neurointerv Surg. 2018;10(7):687-92. https://doi. org/10.1136/neurintsurg-2017-013272.

17. Gross BA, Ares WJ, Ducruet AF, Jadhav AP, Jovin TG, Jankowitz BT. A clinical comparison of atlas and LVIS Jr stent-assisted aneurysm coiling. J Neurointerv Surg. 2019;11(2):171-4. https://doi.org/10.1136/neurintsurg-201 8-014208.

18. Griessenauer CJ, Ogilvy CS, Adeeb N, Dmytriw AA, Foreman PM, Shallwani $\mathrm{H}$, et al. Pipeline embolization of posterior circulation aneurysms: a multicenter study of 131 aneurysms. J Neurosurg. 2018;130(3):923-35. https://doi.org/10.3171/2017.9.JNS171376.

19. Kiyofuji S, Graffeo CS, Perry A, Murad MH, Flemming KD, Lanzino G, et al. Meta-analysis of treatment outcomes of posterior circulation non-saccular aneurysms by flow diverters. J Neurointerv Surg. 2018;10(5):493-9. https:// doi.org/10.1136/neurintsurg-2017-013312.

20. Bender MT, Colby GP, Jiang B, Lin LM, Campos JK, Xu R, et al. Flow diversion of posterior circulation cerebral aneurysms: a single-institution series of 59 cases. Neurosurgery. 2019;84(1):206-16. https://doi.org/10.1093/neuros/ nyy076
21. Li W, Wang Y, Zhang Y, et al. Efficacy of LVIS vs. Enterprise stent for endovascular treatment of medium-sized intracranial aneurysms: a hemodynamic comparison study. Front Neurol. 2019;10:522.

22. Wiebers DO, Whisnant JP, Huston J 3rd, et al. Unruptured intracranial aneurysms: natural history, clinical outcome, and risks of surgical and endovascular treatment. Lancet. 2003;362(9378):103-10. https://doi.org/10.1 016/S0140-6736(03)13860-3.

23. Zhang X, Zhong J, Gao H, Xu F, Bambakidis NC. Endovascular treatment of intracranial aneurysms with the LVIS device: a systematic review. J Neurointerv Surg. 2017;9(6):553-7. https://doi.org/10.1136/neurintsurg-2016012403.

24. Wang CB, Shi WW, Zhang GX, Lu HC, Ma J. Flow diverter treatment of posterior circulation aneurysms. A meta-analysis. Neuroradiology. 2016;58(4): 391-400. https://doi.org/10.1007/s00234-016-1649-2.

25. White AC, Kumpe DA, Roark CD, Case DE, Seinfeld J. Patterns, predictors, and outcomes of postprocedure delayed hemorrhage following flow diversion for intracranial aneurysm treatment. World Neurosurg. 2018;115: e97-e104. https://doi.org/10.1016/j.wneu.2018.03.190.

26. Chalouhi N, Zanaty M, Jabbour PM, Starke RM, Tjoumakaris SI, Rosenwasser $\mathrm{RH}$, et al. Intracerebral hemorrhage after pipeline embolization: management of antiplatelet agents and the case for point-of-care testing-case reports and review of literature. Clin Neurol Neurosurg. 2014;124:21-4. https://doi.org/10.1016/j.clineuro.2014.06.021.

27. Wang J, Jia L, Duan Z, Wang Z, Yang X, Zhang Y, et al. Endovascular treatment of large or giant non-saccular vertebrobasilar aneurysms: pipeline embolization devices versus conventional stents. Front Neurosci. 2019;13: 1253. https://doi.org/10.3389/fnins.2019.01253.

28. Xue G, Tang H, Liu P, et al. Safety and long-term efficacy of stent-assisted coiling for the treatment of complex posterior cerebral artery aneurysms. Clin Neuroradiol. 2019. https://doi.org/10.1007/s00062-019-00825-w.

\section{Publisher's Note}

Springer Nature remains neutral with regard to jurisdictional claims in published maps and institutional affiliations.
Ready to submit your research? Choose BMC and benefit from:

- fast, convenient online submission

- thorough peer review by experienced researchers in your field

- rapid publication on acceptance

- support for research data, including large and complex data types

- gold Open Access which fosters wider collaboration and increased citations

- maximum visibility for your research: over $100 \mathrm{M}$ website views per year

At BMC, research is always in progress.

Learn more biomedcentral.com/submissions 